\title{
Effect of septoplasty on functional outcomes and physical fitness level
}

\author{
Bihter AKINOĞLU1 ${ }^{1}$ Murad MUTLU², Tuğba KOCAHAN ${ }^{3}$
}

${ }^{1}$ Ankara Yıldırım Beyazıt University, Faculty of Health Sciences, Department of Physiotherapy and Rehabilitation, Ankara, Turkey
${ }^{2}$ Dışkapı Yıldırım Beyazıt Training and Research Hospital, Otolaryngology Clinic, Ankara, Turkey
${ }^{3}$ The Ministry of Youth and Sports, Sports General Directorship, Department of Health Services, Center of Athlete Training and Health
Research, Ankara, Turkey

SUMMARY

This study aimed to determine the effect of septoplasty on functional outcomes and physical fitness level. Seventeen patients (mean age $=27.52 \pm 7.77$ years) with obvious nasal septal deviations (NSDs) were enrolled in the study. All patients underwent a detailed otorhinolaryngologic examination, and the functional movement skills and physical fitness level were evaluated before operation and 6 months after the operation. Functional outcomes were assessed using the timed up and go test and timed up and down stairs test. The physical fitness level of patients was assessed using 6-min walking test (6-mWT), muscle strength tests, muscle endurance tests, flexibility tests, agility test, speed tests, and balance tests.

A significant improvement was observed in functional outcomes and most of physical fitness parameters after septoplasty operation $(P<0.05)$.

These findings suggested a positive effect of septoplasty on the physical fitness level and functional outcomes, which could be an important point for the relationship of physical fitness level and functional outcomes with NSD.

Key words: Functional outcomes, nasal septal deviation, septoplasty, physical fitness

\section{INTRODUCTION}

Nasal septum is one of the most essential physiological and supportive structures of the nose. Nasal septal deviation (NSD) causes obstruction of air passages in nostrils, and the nose loses its normal structure and functions due to the sliding of the nasal septum to the right or left side. Trauma, lengthening of birth moment, abnormal pressure during birth moment, and abnormal growth of maxillary bone can cause NSD. The prevalence of NSD in society has been reported as 18.8\%-57.6\% (1).

The major complaint of patients with NSD is the obstruction of the nose among the most frequent causes of the applications made to the otolaryngology polyclinic (2). Continuous obstruction of the nose causes breathing difficulties, resulting in breathing through the mouth.

The purpose of NSD operation (septoplasty) is to resolve the symptoms due to obstruction by harming the nose physiology minimally (3-4). Although dyspnea and fatigue during sport and other activities are general complaints of patients with NSD, no study has examined the effects of NSD or septoplasty operation on the physical fitness level. Only one study investigated the physical performance of the children who breathed normally and who breathed through the mouth. The physical performance was found to be diminished in the children who breathed through the mouth compared with their healthy peers (5). Therefore, it was planned to determine how functional outcomes and physical fitness level of patients were affected following the septoplasty operation due to theshortness of breath during workout and other activities because the air taken through the mouth was not humidified, warmed, and filtered adequately in NSD (3-5).

Correspondence:

Bihter AKINOĞLU

Ankara Yıldırım Beyazıt Üniversitesi, Sağlık Bilimleri Fakültesi, Fizyoterapi ve Rehabilitasyon BölümüEtlik Milli İrade Binası, Ankara, Türkiye. e-mail: rgkardelen@yahoo.com 
The aim of the present study was to determine the effect of septoplasty on functional outcomes and physical activity level.

It was hypothesized that the functional outcomes and physical fitness level of patients with NSD would increase after septoplasty.

\section{MATERIAL AND METHODS}

Thirty-seven patients with nasal deviation, who applied to the otorhinolaryngology polyclinic of Dışkapı Yıldııım Beyazıt Training and Research Hospital, Ankara, Turkey for the septoplasty operation, were included in the study. Of these, 20 patients did not attend the postoperative control examination. Hence, the study was completed with 17 patients.

Patients with hypertension, coronary artery disease, diabetes mellitus, cerebrovascular infarcts, and other nasal pathologies, such as allergic rhinitis, excessive turbinate hypertrophy, concha bullosa, chronic rhinosinusitis, or nasal polyposis; cigarette smokers; and routine drug users were excluded from the study. In addition, the patients who could not cooperate with the tests, had any other orthopedic or systemic problems, or underwent any other surgery were excluded from the study.

The anterior rhinoscopy and flexible fiberoptic nasopharyngoscopy assessments revealed markedly deviated nasal septum in all patients. During septoplasty, a hemi transfixion incision was made under local anesthesia for all patients.

Functional outcomes were determined using the timed up and go (TUG) test and timed up and down stairs (TUDS) test (6-7). Sixmin walk test (6mWT), muscular strength, muscular endurance, flexibility, speed, agility, and balance tests were performed to assess the physical fitness level. Patients wore comfortable outfits and sneakers during the assessments.

The $6 \mathrm{mWT}$ was performed as a submaximal cardiovascular endurance test (8).

Trunk extensors muscle strength and upper abdominal muscle strength were assessed using the manual muscle strength test developed by Dr. Lovett (9).

Abdominal muscles endurance and dorsal extensors endurance were assessed using the sit-up test and reverse sit-up test, respectively, and the number of movements made within 30 s was recorded (10-11).
The sit-and-reach test was performed to assess the flexibility of the lumbar region, hamstring muscles, and gastrocnemius muscle, and dorsal extension movement test was performed to test trunk flexibility (9).

The speed of the patients was assessed using 20-meter fast walking and fast up and down stairs test (12). The agility of the patients was assessed using the $10 \times 5 \mathrm{~m}$ shuttle run test (13). The functional mobility and balance of the patients were assessed using the forward functional reach test (6).

All patients were informed about the purpose, potential benefits, and assessments methods of the study. The patients were asked to sign an informed consent. The human ethics committee of Training and Research Hospital approved this study in accordance with the Declaration of Helsinki (31.08.2010/03; 93).

\section{Statistical analysis}

The data collected from the groups before and after the treatment were analyzed using Statistical Package for Social Sciences (SPSS, IL, USA) for Windows Release 16.0 statistical package program. The variables determined during the measurements were expressed as mean \pm standard deviation (X \pm SD), and the percentage (\%) value determined by counting was estimated.

The nonparametric Wilcoxon signed-rank test was performed for comparing numerical variables of the patients before and after the operation. The P significance value was accepted as 0.05 in all statistics.

\section{RESULTS}

A total of 17 patients, including 4 women and 13 men with NSD who are physically inactive, were assessed in the present study in terms of functional movement skills and physical fitness level before the operation and 6 months after the operation. The age of the patients was $27.52 \pm 7.77$ years, and the average body mass index was recorded as $24.45 \pm 3.92 \mathrm{~kg} / \mathrm{m}^{2}$. Weight and body mass index data, which were thought to affect physical fitness parameters, did not change in the patients following the postoperative evaluation.

The functional outcomes of the patients improved after the operation $(P<0.05)$. Moreover, when the physical fitness parameters of the patients before and after the operation were compared, it was found that 6-min walking test distance, abdominal muscular strength, 
each of the three muscular endurance test values, flexibility test results, $10 \times 5 \mathrm{~m}$ shuttle run test results, speed tests, and forward functional laying test values were better after the operation than before the operation $(P<0.05)$. However, the muscular strength of trunk extensors before and after the operation was not different $(P>0.05)$ (Table 1).

\section{DISCUSSION}

This novel study investigated the effects of septoplasty on functional outcomes and physical fitness level. It was hypothesized that the functional outcomes and physical fitness level would increase after septoplasty. The findings of the study revealed that the functional outcomes improved and the physical fitness level increased after the septoplasty operation.

NSD is a clinical state that results in the obstruction of air passages in nostrils and also causes sliding of the nasal septum to the right or left side. Consequently, the nose loses its normal structure and function. It has been reported in the literature that persons with NSD suffer from shortness in breath and general fatigue during workout and other physical activities (1).
It has been shown that the pulmonary functions improve following septoplasty in patients with NSD (13). Özkeçeci et al. evaluated the pulmonary arterial pressure (PAB) and right ventricular function of patients with NSD. They showed that patients with NSD had increased PAB levels and impaired function of the right ventricle compared with the healthy subjects. Moreover, the impaired outcomes improved after septoplasty (8).

High energy consumption during activities such as walking and easy and early fatigue can lead to a decrease in the activity level and exercise performance and also affect physical fitness unfavorably due to difficulty in breathing in patients with NSD. Therefore, the data of 17 patients with NSD before and after the septoplasty operation were compared in the present study.

Recent studies showed that deformities in nose physiology would affect the lungs adversely (14-16). Some pathologies in the upper respiratory tract occurred frequently along with liver disorders; they were also involved in the pathogenesis of these illnesses (17-19) Şapç et al. assessed preoperative and postoperative lung function tests of 31 patients with nasal obstruction treated with surgery, using a flow-volume spirometer, and showed that the pathology

\begin{tabular}{|c|c|c|c|c|c|c|}
\hline \multirow{2}{*}{\multicolumn{2}{|c|}{ Functional outcome tests }} & \multirow{3}{*}{$\begin{array}{l}\text { TUG (sn) } \\
\text { TUDS (sn) }\end{array}$} & \multirow{3}{*}{$\begin{array}{l}\text { Preoperative } \\
3.29 \pm 0.66 \\
5.31 \pm 1.07\end{array}$} & \multirow{3}{*}{$\begin{array}{l}\text { Postoperative } \\
2.96 \pm 0.35 \\
4.76 \pm 0.76\end{array}$} & \multirow{3}{*}{$\begin{array}{l}P^{*} \\
0.017 \\
0.025\end{array}$} & \multirow{3}{*}{$\begin{array}{l}Z \\
-2.379 \\
-2.249\end{array}$} \\
\hline & & & & & & \\
\hline & & & & & & \\
\hline \multirow{12}{*}{$\begin{array}{l}\text { Pyhsical } \\
\text { fitness tests }\end{array}$} & $\begin{array}{l}\text { Cardiovascular } \\
\text { endurance test }\end{array}$ & 6-Min walk test distance (m) & $666.47 \pm 100.74$ & $799.41 \pm 90.58$ & 0.001 & -3.305 \\
\hline & Muscle strength & Trunk extensors & $4.47 \pm 0.71$ & $4.70 \pm 0.46$ & 0.102 & -1.633 \\
\hline & & Abdominal flexsors & $4.23 \pm 0.83$ & $4.70 \pm 0.46$ & 0.031 & -2.126 \\
\hline & Muscular & Back extension endurance (Pcs/min) & $26.23 \pm 5.10$ & $30 \pm 9.38$ & 0.031 & -2.161 \\
\hline & measurements & Abdominal shuttle (Pcs/min) & $19.35 \pm 5.41$ & $21.17 \pm 5.21$ & 0.038 & -2.077 \\
\hline & & Squat (Pcs/min) & $19.88 \pm 4.47$ & $25.11 \pm 5.21$ & 0.033 & -2.077 \\
\hline & Flexibility tests & Sit-and-reach test (cm) & $2.70 \pm 5.78$ & $5.52 \pm 6,35$ & 0.006 & -2.767 \\
\hline & & Back extension flexibility (cm) & $16.94 \pm 3.41$ & $20.11 \pm 4.01$ & 0.008 & -2.647 \\
\hline & Agility test & $10 \times 5-m$ shuttle test $(\mathrm{sn})$ & $24.79 \pm 7.62$ & $19.64 \pm 2.84$ & 0.001 & -3.290 \\
\hline & Speed tests & Walking speed (sn) & $8.06 \pm 1.54$ & $6.90 \pm 1.11$ & 0.001 & -3.243 \\
\hline & & Up and down stairs speed (sn) & $4.87 \pm 1.03$ & $4.42 \pm 0.68$ & 0.002 & -3.148 \\
\hline & Balance tests & Functional reach test $(\mathrm{cm})$ & $37 \pm 5.37$ & $44.29 \pm 7.24$ & 0.001 & -3.313 \\
\hline
\end{tabular}


causing the upper respiratory tract obstruction affected lung physiology (16). In the present study, the lung function was not measured directly but the tests used could reflect the functional performance of the patients. The TUG and TUDS results improved after surgery. These results were in accordance with previous studies indicating that septoplasty might improve the functional capacity of the patients.

Cardiovascular endurance, one of physical fitness parameters, is crucial for the persons to be social and perform their daily life activities without difficulty. Cardiovascular response occurring as a result of exercise tests is a major criterion used in the exercise prescriptions of both healthy and ill patients (13). The 6mWT was performed in the present study to assess cardiovascular endurance. The 6-min walk distances of the persons increased significantly after the operation. Considering that patients with nasal deviation suffer from difficulty in breathing during physical activities, it was believed that a reduction in these complaints after the operation could have affected the walking distance of the patients. Despite studies in the literature investigating various lung functions and respiration function tests of patients with nasal deviation before and after the operation (5,20-22), no study explored the physical fitness and functional outcomes. However, corresponding to the present study, Tüzüner et al. (23) assessed the pulmonary function of patients who underwent septoplasty operation. They reported an improvement in 6-min walk distance and pulmonary functions of patients after the operation.

It was shown that muscle strength is a determinant of physical activity level in healthy persons (24). It was seen that patients with weak muscular force had more difficulty in performed motor activities (25). Furthermore, patients with chronic respiratory system illnesses had diminished the muscular strength and did not use their skeletal muscles (26). In the present study, the muscle strength of abdominal muscles was found to be better after the operation, although the muscle strength of trunk extensors did not change. The endurance of trunk extensors and abdominal muscles was found to be better after the operation. The studies conducted on healthy and patient groups reported a relationship between muscle strength and muscular endurance (27). The endurance of trunk extensors was found to be higher after the operation in the present study. It was believed that unchanging muscular force after the operation had something to do with the measurement method used. The manual muscle strength testing used in the present study yielded a more general result compared with technological devices. Had a more sensitive system, such as isokinetic systems, been used in the present study, the results would have been much different. Moreover, it was presumed that this was the outcome of the effect of oxygen consumption capacity of the persons on the endurance parameters; this capacity could have increased after the operation (28).

The present study showed that the sit-and-reach test and the flexibility of trunk extension movement improved after the operation. Moreover, the values of $10 \times 5$-m shuttle run test, which was used as an agility test, improved after the operation. This outcome led to the belief that the physical fitness level of some persons increased after the operation due to more comfortable movement and hence improvement in their breathing and pulmonary functions.

Kürkçüoğlu et al. (20) compared the respiration function tests of patients with nasal deviation before and after the operation. They concluded that correction of NSD surgically could facilitate not only the resolution of nose obstruction but also the improvement in lung functions. In the present study, it was thought that speed and balance parameters, like all physical fitness parameters, could be influenced by the affected lung functions and this influence disappeared after the operation.

The primary limitation of the present study was that the parameters could not be assessed despite the opportunity to compare the study group with an age-matched healthy population or with an age-matched population with NSD. Another limitation was that the present study used manual muscle test assessments for muscle strength measurement.

\section{CONCLUSIONS}

The present study demonstrated that the functional outcomes and physical fitness parameters improved after the septoplasty operation. Further investigation is needed to determine which exercises can improve the physical fitness level of the patients with NSD before and after septoplasty operation. In addition, studies on 
a larger number of patients with NSD, which comprise a group of patients participating in an exercise program after the operation compared with the healthy control group and use more specific measurement techniques, would help to address this issue.

Acknowledgments: The authors would like to thank Bahar Külünkoğlu for her assistance in analyzing the data.

\section{REFERENCES}

1. Tahir Mahmood K, Fareed T, Tabbasum R. Management of Deviated Nasal Septum. J Pharm Sci and Res 2011;3(1): 918922.

2. Aydoğdu İ, Saltürk Z, Uyar Y, Yıldırım G, Doğan Ö. Importance of Nasal Septal Deviation Type on Planning of Surgery. Journal of Clinical and Analytical Medicine 2015;6(1): 30-2.

3. Kazkayası M, Dinçer C, Sezikli H, Arıkan K, Kürşat $O$, Çağlayan $O$. The effect of suturing technique and nasal packing on oxidative stress in septoplasty operations. Kulak Burun Bogaz Ihtis Derg 2008;18(1):35-39

4. Stewart MG, Smith TL, Weaver EM, Witsell DL, Yueh B, Hannley $M T$, et al. Outcomes after nasal septoplasty: results from the nasal obstruction septoplasty effectiveness (NOSE) study. Otolaryngol Head Neck Surg 2004;130(3):283-90.

5. Boas APDV, de Lima Marson FA, de Oliveira Ribeiro MAG, Sakano E, Conti PBM, Toro ADC, et al. Walk test and school performance in mouth-breathing children. Brazilian journal of otorhinolaryngology 2013;79(2):212-218.

6. Bennie S, Bruner K, Dizon A, Fritz H, Goodman B, Peterson S. Measurements of Balance: Comparison of The Timed "Up and Go" Test and Functional Reach Test with the Berg Balance Scale. J Physthersci 2003;15:93-97.

7. Bonnyaud C, Zory R, Pradon D, Vuillerme N, Roche N. Clinical And Biomechanical Factors Which Predict Timed Up and Down Stairs Test Performance in Hemiparetic Patientsce. Gait and Posture 2013;38: 466-470.

8. Özkeçeci G, Akçi O, Bucak A, Ulu S, Yalım Z, Aycicek A, et al. The Effect of Septoplasty on Pulmonary Artery Pressure and Right Ventricular Function in Nasal Septum Deviation. The American Journal of Cardiology 2016;117: 32.

9. Rasekaba T, Lee A, Naughton MT, Williams TJ, Holland AE. The Six-Minute Walk Test: A Useful Metric for The Cardiopulmonary Patient. Internmed J 2009; 39:495-501.

10. Otman AS, Köse N. Tedavi Hareketlerinde Temel Değerlendirme Prensipleri. Ankara: Yücel Ofset Matbaacılık. 2008.

11. Oskay D, Yakut Y. Bel Ağrısı Olan ve Olmayan Kadınların Fiziksel Uygunluk Parametrelerinin Karşılaştırılması. Göztepe Tıp Dergisi 2011;26(3):117-122.

12. Okudan N. Exercise Tests Performed in Chest Diseases Clinics. Solunum Dergisi 2012; 14:32-34.

13. Bakirhan S, Angin S, Karatosun V, Unver B, Gunal I. Physical Performance Parameters During Standing Up in Patients with Unilateral and Bilateral Total Knee Arthroplasty. Acta Orthop Traumatol Turc 2012;46(5):367-372.
14. Widdicombe JG. The Physiology of The Nose. Clinical Chest Medicine 1986; 7: 159-170.

15. Lumsden JM, Derksen FJ, Stıck JA, Robinson NE. Use of FlowVolume Loops To Evaluate Upper Airvay Obstruction in Exercising Standard Breds. Am J Vel Res 1990; 54: 766-775.

16. Mellisant CF, Van Noord JA, Van De Woestijine KP, Demetds M. Comparison of Dynamic Lung Function Indices during Forced and Quiet Breathing in Upper Airway Obstruction. Asthma and Emphysema. Chest 1990; 98: 77-83.

17. Karaman M, Tek A, Tuncel A, Erdem Habesoglu T. Evaluation of patients with septal deviation using respiratory function tests before and after septoplasty. Kulak Burun Bogaz Bas Boyun Cerrahi Derg 2011;19(1):1-5.

18. Akman M, Yılmaz T, Sapçı T, Göylüsün V. Bronş Astmalı Olgularda Üst Solunum Yolu Patolojileri. KBB ve Boyun Cerrahisi Dergisi 1996; 4:62.

19. Spector SL. The Role of Allergy in Sinusitis in Adults. J Allergy Clin Immunol 1992; 90: 518-20.

20. Kurkcuoğlu S, Titiz A, Olcay I. Effect Of Nasal Septal Deviation on Respiratory Function Tests and Arterial Blood Gases. KBB ve BBC Dergisi 2007;15(3):134-138.

21. Şapçı T, Alan O, Karavuş A, Ocaklı Ö, Ocaklı BY, Akbulut, UG, et al. Nazal Obstruksiyonlu Olgularda Flow Volume Spirometri. K.B.B. ve Baş Boyun Cerrahisi Dergisi 1999, 7(1): 11-16.

22. Marino $D M$, Marrara $K T$, Ike $D$, De Oliveira $A D$, Jamami $M$, DiLorenzo VAP. Study of Peripheral Muscle Strength and Severity Indexes in Individuals with Chronic Obstructive Pulmonary Disease. Physiotherapy Research International 2010;15: 135-143.

23. Tuzuner A, Bilgin G, Demirci S, Yuce GD, Acikgoz C, Samim EE. Improvement of Pulmonary Functions Following Septoplasty: How Are Lower Airways Affected? Clinical and experimental otorhinolaryngology 2016;9(1):51-55.

24. Dogan OT, Yıldırım A, Epozturk K, Dogan M. An other advantage of nasal septal suturing: pulmonary function unaffected. B-ENT 2012;8(1):21-4.

25. Sandler RB, Burdett R, Zaleskiewicz M, Sprowls-Repcheck C, Harwell, M. Muscle Strength As An Indicator of The Habitual Level of Physical Activity. Medicine and Science in Sports and Exercise, 1991;23:1375-1381.

26. Rantanen T, Guralnik JM, Sakari-Rantala R,Leveille S, Simonsick EM, Ling S, et al. Disability, Physical Activity, and Muscle Strength in Older Women: The Women's Health and Aging Study. Archives of Physical Medicine and Rehabilitation, 1999;80: 130-135.

27. Adedoyin RA, Erhabor GE, Ojo OD, Mbada CE, Awotidebe TO, Obaseki DO, et al. Assessment of Cardiovascular Fitness of Patients with Pulmonary Tuberculosis Using Six Minute Walk Test. Taf Preventive Medicine Bulletin 2010;9(2):99-106.

28. Bulcun E, Kazkayasi M, Ekici MA, Tahran FD, Ekici M. Effects of septoplasty on pulmonary function tests in patients with nasal septal deviation. Journal of Otolaryngology-Head and Neck Surgery 2010;39(2): 196-202. 